\title{
SOME MENTAL ASPECTS OF LEPROSY
}

\author{
E. Muir.
}

In the treatment of leprosy it is perhaps as important to study the patient's mental condition as his physical. Leprous infection does not directly cause organic disease of the central nervous system, though widespread affection of the peripheral nerves is said sometimes to give rise to secondary degeneration of certain tracts in the spinal cord. 
Leprosy is a disease apart. When a word is required to express the utmost limit of horror and loathing, the word "leper" is commonly used. In many countries the innocent victim is loaded with reproach for having acquired it; if he had not been a very wicked person the gods would not have punished him in this way. The community reacts to the leper with a feeling of abhorrence, and it is the counter-reaction of the leper to this attitude of the community which is largely responsible for his mental condition.

Except in a few places here and there where the leper is tolerated, and, because of ignorance or indolence, is allowed to mix with the public, it is the almost universal custom that he is shunned and ostracised. It may be useful, therefore, to study first of all the reason for this mental reaction of the community. It is not on account of great infectiousness. Leprosy is not a notifiable disease in England, where open cases of tuberculosis are notifiable; the latter is undoubtedly a much more infectious disease. Yet tuberculosis is not dreaded like leprosy. Nor is it high mortality that makes leprosy dreaded; influenza and a host of other infectious diseases are much more fatal, yet they are not feared as leprosy is.

It is the disfigurement of leprosy that makes it so repulsive. The hands and face, the chief organs of self-expression, are deformed and repulsive in many advanced cases. "Skin for skin, yea all that a man hath will he give for his life" said Satan regarding that perfect and upright man, Job. And he added, "put forth thine hand now and touch his bone and his flesh, and he will curse thee to thine face." Whether the author of Job meant to describe leprosy or not, he understood the psychology of a chronic, non-fatal, disfiguring disease. The leper is seldom ill enough to be confined to bedw and so he moves about in the community. Also, as it is not in itself a fatal disease, the duration of leprosy is prolonged. The unfortunate victim is not considered as having an " attack of leprosy," but as " being a leper." $\mathrm{He}$ belongs to a class apart like the blind, the deaf-mute and the insane, only his infirmity is much more detested than theirs. While the majority of those suffering from leprosy may never reach a stage at which they are actually repulsive, yet the ignorant public seldom take degrees and types into consideration: he is a leper, and therefore to be shunned.

In face of this attitude of the community, there is bound to be a profound mental effect on the leper himself. His first reaction is concealment, and the constant dread lest his condition become known tends to cause repression and a general unhealthy mental state. Then, in proportion as he becomes known as a 
leper, and the ostracism of the community becomes operative, he suffers from a feeling of inferiority. If he loses his employment and becomes dependent on the charity of others, his instinct of self-respect becomes undermined.

The consequent mental depression is apt to produce a parallel condition of physical depression and thus still further to lower the patient's resistance to leprosy. The disease accordingly increases and becomes the more difficult to conceal; or, if its presence has become known, it induces still more severe ostracism; a vicious spiral is thus formed.

In treating leprosy it is essential to recognise, and if possible to remedy, this deplorable mental condition. For this purpose the agricultural settlement is an ideal solution. Here all need of concealment is removed. The doctor and his staff know the worst and still are sympathetic. $\mathrm{He}$ is surrounded by fellow patients, so that ostracism is at once removed. The sympathy of fellow-sufferers and the inspiration of mutual endeavour towards recovery, help to bind all together in a common bond of friendship.

The settlement, besides giving mental relief and opportunities for self-expression, provides modern treatment of leprosy and complicating diseases. The patient's self-respect is restored by obtaining suitable employment. He feels that he has a useful part to play in the community; healthy physical exercise hardens his body and enables him to fight the disease.

Those who have visited a modern agricultural and industrial leper settlement with its whole-time expert workers and its voluntarily admitted patients, and have compared it with the original compulsory leprosarium, must have noticed a very marked contrast. In the former all is cheerfulness, hopefulness, alertness and willingness to co-operate. In the latter, though as a rule far more is done for and spent on the patients, there is an atmosphere of churlishness and a constant feeling of grievance. In the former most misdemeanours can be sufficiently punished by stopping the treatment, while in the latter the patient must be bribed or forced to take treatment. Needless to say, the voluntary institution gives considerably better results and far more patients recover. In the compulsory leprosarium the patient may be satiated with physical comforts but the years of care-free ease, the smouldering feeling of grievance that his liberty has been taken away, the absence of hope for the future and the enforced detachment from the world of reality outside the walls of the institution, lead inevitably to mental degeneration; the unemployed becomes unemployable and a discontented useless parasite on the community. 
Prof. Cazanavette found 82 (I9.5 per cent.) of the 427 patients at the U.S. National Leprosarium, Louisiana, to be diseased mentally, the largest group being I 8 suffering from mental depression. Besides the 19.5 per cent. with mental abnormalities, 3 per cent. were affected with definite psychoses, while a larger percentage presented abnormal mental conditions, including mental inferiority and border-line states. The leprosarium is among the best equipped and staffed and lavishly provided institutions in the world.

Leprosy differs from most other diseases in the importance of the patient's role in the chance of recovery. In appendicitis recovery depends chiefly on the surgeon, in typhoid on the nurse, in leprosy on the patient. The doctor can advise the patient what to do and encourage him to do it; but day in and day out it is the patient himself who must carry out the constant struggle against the disease. To enable him to do this he needs the cheerful, busy time-planned atmosphere of the leper settlement, with its encouragement of fellow-strugglers towards the common ideal of restored health and the inspiration of those who have already advanced further up the steep slope towards freedom from disease.

There are certain mental qualities which increase the patient's chances of recovery. Intelligence is necessary if he is to understand the nature of the disease and the measures necessary for successfully combating it. Without determination and perseverance he cannot carry on the struggle for years on end. Without hopefulness and cheerfulness he cannot withstand the feeling of depression and often of disappointment attendant on his condition. Important as good physical health and strength are, the requisite mental equipment is no less important. Looking back over some of the most remarkable cases of recovery one has known, patients who were originally bad lepromatous cases, but.who, after years of treatment, finally got rid of the disease and have now remained free from active signs for many years, one remarks that they have all been patients of character, intelligence, common sense and perseverance, who were determined to get better and obeyed all instructions, however irksome, with implicit obedience.

In the treatment of any patient it is therefore necessary to study his mental equipment. If he lacks intelligence the physician must explain things the more frequently and carefully, knowing that without understanding it is impossible to gain satisfactory co-operation from the patient, and the treatment is likely to fail. Or the relatives must be instructed, especially any of them who appear intelligent and likely to help the patient to carry out directions. 
If the patient is depressed or gives way to fear, he must be encouraged, not with false hopes but by pointing to other cases who have made satisfactory improvement.

The kind-hearted sentimentalist who pities the leper as a hopeless incurable, who panders to his besetting sins of depression and dejection, who gives charity in such a way as to clog up the wheels of self-respecting action, is the greatest stumbling block in the way of recovery.

Lastly, we should remember that although leprosy is sometimes a painful disease, the mental distress is far greater than the physical. Also the mental distress is often in direct proportion to the education and culture of the victim. He tends to be abnormally sensitive and has periods of exaltation alternating with periods of depression. He is on the look out for new " cures " for leprosy, hails them with the greatest enthusiasm, is first sure that they are doing him good and is proportionately disappointed when he finds them of little avail.

The victim of leprosy deserves and requires our sympathy, but much more he requires understanding; and the object of this short paper is to interpret some of the least understood aspects of this obscure and difficult disease. 